\title{
Rapid decolorization of synthetic melanoidin by bacterial extract and their mediated silver nanoparticles as support
}

\author{
R. Palani velan ${ }^{\mathrm{a} *}$ P.M. Ayyasamy ${ }^{\mathrm{a}}$, R. Kathiravan ${ }^{\mathrm{b}}$, B. Subashni ${ }^{\mathrm{c}}$ \\ ${ }^{a}$ Department of Microbiology, Periyar University, Salem, Tamil Nadu, India. \\ ${ }^{\mathrm{b}}$ Department of Microbiology, M.S. Swaminathan Research Foundation, Chennai, Tamil Nadu, India. \\ ${ }^{\mathrm{c}}$ Department of Biotechnology, Sri Ramachandra University, Chennai, Tamil Nadu, India.
}

\author{
ARTICLE INFO \\ Article history: \\ Received on: $31 / 03 / 2015$ \\ Revised on: 12/04/2015 \\ Accepted on: 21/04/2015 \\ Available online: 27/04/2015 \\ Key words: \\ Melanoidin, Molasses spent \\ wash, Decolorization, Silver \\ nanoparticle, Immobilization.
}

\begin{abstract}
The present study was aimed at utilization of biosynthesized silver nanoparticles (AgNPs) and its mediated synthetic melanoidin decolorization using bacterial extract in an immobilized condition. Biosynthesis of silver nanoparticles was done by using the Bacillus sp. BAC1 via extracellular methodology. Brown color biosynthesized silver nanoparticles were characterized using UV-Visible spectroscopic analysis. Further characterization using Transmission electron microscopy (TEM), Scanning electron microscopy (SEM), Energy dispersive X-ray spectroscopy (EDX), Fourier transform infrared spectroscopy (FT-IR) and Atomic force microscopic (AFM) analysis revealed that nanoparticles were spherical in shape with smooth surface morphology. Bacterial extracellular supernatant exhibited more than $65 \%$ of melanoidin decolorization (in $12 \mathrm{~h}$ ) under normal conditions. In contrast, under similar conditions, biosynthesized AgNPs showed 82\% removal. The cell free extract immobilized with synthesized AgNPs yields maximum melanoidin removal $92 \%$ in $12 \mathrm{~h}$; this emphasizes nano-coupled biomaterial immobilization as a suitable technique for rapid melanoidin decolorization.
\end{abstract}

\section{INTRODUCTION}

Dark brown colored effluent generated from sugarcanebased industries is known as molasses spentwash, it contains high concentrations of biopolymer melanoidin, heavy metals, sulfate, phenolics, solids, BOD and COD [1]. Melanoidin is a naturally colored pigment, generated in maillard reaction between amino and carbonyl groups of organic substances [2]. The discharging melanoidin based effluent leads to water pollution problems in aquatic environments, due to the reduction of sunlight penetration and photosynthetic activity. In addition, colored spent wash causes soil pollution by the reduction of alkalinity, inhibition of seed germination and vegetation [3]. Several physical-chemical technologies such as photolysis, photocatalytic degradation, flocculation, membrane filtration, ultrafiltration, mineral sorbents or biosorbents, chemical oxidation and advanced oxidation have been studied for decolorization of melanoidin containing colored effluent [4]. However, microbial decolorization using bacteria, fungi, yeast is considered as eco-friendly and is also capable of mineraliza-tion of end products [5].

* Corresponding Author

Dr. R. Palani velan, Bioremediation Laboratory, Department of

Microbiology, Periyar University, Salem - 636 011, Tamil nadu, India.

E-mail: starvel2005@yahoo.co.in, Mobile: +919952517712
The main limitations are the increase in prohibitive cost, carbon dioxide, volatile acids and biomass content after treatment. Immobilization technology is an alternative to overcome these problems rather than applying free cells in the degradation process [6]. Now-a-days various immobilization systems have been employed to enhance the decolorization process. A new development in this area is the combined action of microbial source with nanoparticle immobilization in order to enhance degradation [7]. Nanotechnology also facilitates the utilization of wide range of nanoparticles as catalyst in waste water treatment process [8], because of higher surface area, high catalytic efficiency, mass transfer effect, effective enzyme storage, and high surface reaction activity $[9,10]$. Using nanoparticles as a supplement in biodegradation is found to influence the microbial population and in turn the rate of bio degradation [11]. Similarly, the use of nanoparticles with enzyme immobilization technology has also been effective in color removal process $[12,13]$. Numerous reports have described the application of silver nanoparticles in diverse fields, such as bio-medical, pharmaceutical, cosmetics, electronics, energy sector, dye effluent treatment and other environmental remediation innovations [14,15]. AgNPs posses high thermal and electrical conductivity, chemical stability, catalytic activity, and nonlinear optical behavior [16]. Therefore, the present study was designed to develop a rapid technique for synthetic melanoidin decolorization by integrating the advantages of biosynthesized silver nanoparticles with cell free extract immobilization method. 
In this study, silver nanoparticles were synthesized using Bacillus sp. and characterized. Subsequently, the effect of bacterial extract immobilized with AgNPs on the synthetic melanoidin decolorization was determined. To our knowledge, the use of biosynthesized AgNPs with crude extract immobilization has not been examined previously for synthetic melanoidin decolorization.

\section{MATERIALS AND METHODS}

\subsection{Synthetic melanoidin and chemicals}

All the chemicals and media were procured from $\mathrm{Hi}-$ Media Laboratories, Mumbai, India and Merck, India Ltd. Other chemicals and reagents used were of analytical grade. Synthetic melanoidin, glucose-aspartic-acid (GAA) type was prepared from the method [17], in which 1.0 molar (M) glucose, $1.0 \mathrm{M}$ aspartic acid and $0.5 \mathrm{M}$ sodium carbonate were dissolved in $1.0 \mathrm{~L}$ of distilled water and the solution was refluxed at $100{ }^{\circ} \mathrm{C}$ for $7 \mathrm{~h}$. Further reaction mixture adjusted to $\mathrm{pH} 7.0$ with $1 \mathrm{~N} \mathrm{NaOH}$, the solution was filtered through $0.45 \mu \mathrm{m}$ membrane filter.

\subsection{Microbial culture}

The dual characteristics of decolorization, silver nano particle synthesis ability of bacteria Bacillus sp. BAC1 (GenBank accession number, JX316001) previously isolated from dyes and pigment contaminated soil, Trippur, INDIA, was used in this experiment. The obtained culture was grown and maintained in $\mathrm{LB}$ broth at $30^{\circ} \mathrm{C}$ supplemented with $1 \mathrm{mM}$ concentration $\mathrm{AgNO}_{3}$.

\subsection{Biosynthesis of silver nanoparticles}

Extracellular method was adapted in the synthesis of AgNPs; $100 \mathrm{ml}$ of nutrient broth was prepared in $250 \mathrm{ml}$ Erlenmeyer flask and inoculated with selected bacterial isolate Bacillus sp. BAC1. The cultured flasks were incubated in an orbital shaker with $250 \mathrm{rpm}$ for $24-72 \mathrm{~h}$ at room temperature. The culture was then centrifuged at $7500 \mathrm{rpm}$ for $20 \mathrm{~m}$. Following separation, the cell free supernatant was added to $1 \mathrm{mM}$ concentration of filter-sterilized silver nitrate solution and incubated in the orbital shaker (250 rpm), until color change was noted at room temperature. When brown color was obtained, the supernatant was subjected to nanoparticle formation and characterization.

\subsection{Analysis and characterization of silver nanoparticles}

The optical density value of the supernatant $(2 \mathrm{ml})$ with synthesized silver nanoparticles was analyzed in 200-700 nm using UV spectrophotometer (Cyberlab UV-100 USA). The absorbance values with peaks confirmed reduction of silver nitrate to AgNPs formation with optimal range. Morphology and size of the synthesized AgNPs were further characterized in TEM analysis. Methanol was added to AgNPs it was powdered, dehydrated and grinded well. The infiltrated sample was then placed as a thin film in carbon-coated copper TEM grids. The film was fixed with $1 \%$ osmium tetra oxide allowed to stand for 2 hours (TEM Model: Hitachi H-600). Thin film of sample was prepared in carbon coated copper grid and dried in order to analyse in different resolutions using scanning electron microscopic (SEM model: JEOL-6390). Elemental composition of AgNPs with reduced ions was observed in Energy dispersive X-ray spectroscopy (EDX). For EDX, samples were prepared in carbon coated copper grid (Model: Bruker AXS Inc. USA, Quantax-200). Functional groups associated with silver nanoparticles were identified by FT-IR spectroscopy (FT-IR model EXI).

The least milligrams of silver nanoparticles powder were mixed with equal amount of $\mathrm{KBr}$ (FT-IR grade), subsequently its pellet was prepared from grinded mixture. Infra a red spectrum was observed in the range of $4000-400 \mathrm{~cm}^{-1}$ with a resolution of $4 \mathrm{~cm}^{-1}$ in FT-IR spectroscopy. Atomic force microscopy (AFM) was performed to insight the molecular surface images of the synthesized silver nanoparticles. Nanoparticles were prepared by mixing with methanol mixture followed by coating in silicon slide to form a thin film for AFM analysis (Model: Nanosurf A).

\subsection{Preparation of cell free extract}

Bacillus sp. BAC1 was grown in nutrient broth at $37^{\circ} \mathrm{C}$ for $24 \mathrm{~h}$. Cells were obtained by centrifugation at $5000 \mathrm{rpm}$ for 20 $\mathrm{m}$ and suspended in $50 \mathrm{mM}$ potassium phosphate buffer $(\mathrm{pH} 7.4)$ for sonication ( 8 strokes, each of 30 seconds with $2 \mathrm{~m}$ interval) at a temperature below $4{ }^{\circ} \mathrm{C}$ temperature.

\subsection{Cell free extract with Ag NPs immobilization}

Biosynthesized Ag NPs was washed in distilled water and mixed with $15 \mathrm{~mL}$ of glutaraldehyde solution $(1.25 \%, \mathrm{v} / \mathrm{v})$ in $0.1 \mathrm{M}$ potassium phosphate buffer $(\mathrm{pH} 7.0)$ and stirred for $2 \mathrm{~h}$ at room temperature. Excess glutaraldehyde was removed with the same buffer. Glutaraldehyde-activated nanoparticles were dried at $60{ }^{\circ} \mathrm{C}$ for $1 \mathrm{~h}$. After repeated washing, $0.25 \mathrm{~g}$ of silver nanoparticles was slowly stirred for $24 \mathrm{~h}$ at room temperature after adding $10 \mathrm{ml}$ of cell free extract. Then the produced immobilized nanoparticles were washed by centrifugation-re-suspension, freeze-dried and stored at $4{ }^{\circ} \mathrm{C}$ for later use.

\subsection{Decolorization studies}

Synthetic melanoidin decolorization was performed in four sets of $250 \mathrm{ml}$ Erlenmeyer flask containing $100 \mathrm{ml}$ of medium which is comprised of $10 \%(\mathrm{v} / \mathrm{v})$ melanoidin solution and $90 \mathrm{~mL}$ phosphate buffer solution ( $\mathrm{pH} 7$ ). One among these was taken as abiotic control, second and third was treated with $10 \mathrm{ml}$ cell free extract and $0.25 \mathrm{~g}$ Silver Nanoparticle. Fourth flask was treated with immobilized cell free extract and $0.25 \mathrm{~g}$ AgNPs. The flaks were then incubated at room temperature for $24 \mathrm{hr}$ with constant stirring. Experiments were performed in triplicate and samples were withdrawn at regular $3 \mathrm{hr}$ interval for measuring decolorization rate. Melanoidin removal was monitored by measuring the decrease in color density at $475 \mathrm{~nm}$ wavelength using a UV-Visible spectrophotometer (Cyberlab UV-100 USA). 
The decolorization percentage was determined by implementing the following formula:

Decolorization $(\%)=\frac{\text { Initial absorbance value }- \text { Final absorbance value }}{\text { Initial absorbance value }} \times 100$

\section{RESULTS AND DISCUSSION}

\subsection{Biogenic synthesizing of Silver Nanoparticles}

Dye decolorizing bacterial isolate Bacillus sp. BAC1 was found to have the ability to synthesize silver nanoparticle. Likewise, Bacillus sp. CS 11 was also found to be an efficient organism in extracellular synthesis of stable silver nanoparticles [18]. The change of color of the supernatant from pale yellow to brown confirmed the extracellular reduction of silver ions to silver nanoparticles. Presence of brown color was noticed throughout the $48 \mathrm{~h}$ incubation period. Synthesis of silver nanoparticle takes place by catalysis of nitrate reductase enzyme, which is responsible for the reduction of nitrate to nitrite, and subsequently the formation of AgNPs [19,20]. Maximum dry weight of the synthesized AgNPs was found to be $0.72 \mathrm{~g} / 100 \mathrm{ml}$. Higher concentration of silver ions can be attributed to the utilization of crude culture supernatant, which contains considerable quantity of enzyme [21].

\subsection{Characterization of silver nanoparticles}

The synthesis of silver nanoparticles in colloidal suspension was initially confirmed by UV-Vis spectroscopy measurement at the different time intervals of 24,48 and $72 \mathrm{~h}$. UV - Vis spectrum results (Fig. 1) showed intense absorption peak around $420 \mathrm{~nm}$, due to its specific surface plasmon resonance (SPR) excitation [18]. Morphology and size of AgNPs from TEM analysis depicted that they were spherical in shape. The diameter was found to be in the range of $\sim 35 \mathrm{~nm}$ (Fig. 2).

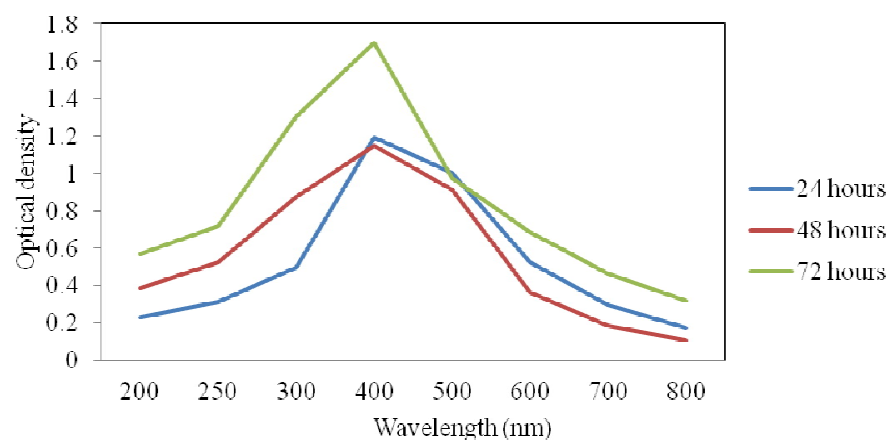

Fig. 1: UV - Visible spectroscopic analysis of silver nanoparticles.

Similar morphology has also been reported earlier [15]. The SEM image of the filtrate revealed well aggregated silver nanoparaticles in different sizes in the range of $26.2-34.6 \mathrm{~nm}$. Also, the distributed silver nanoparticles displayed smooth surface morphology (Fig. 3). Similarly, AgNPs prepared with Ocimum tenuiflorum (Black Tulsi) leaf extract, exhibiting average size of $32.58 \mathrm{~nm}$ was also reported [22]. Elemental composition analysis by EDX presented strongest signal from silver $(\mathrm{Ag})$ region and weaker signals from $\mathrm{Cl}, \mathrm{O}, \mathrm{P}, \mathrm{Na} \& \mathrm{Ca}$ atoms. It also showed that pure crystalline nature was solely composed of silver (Fig. 4).
Similar study exhibiting weak signals from $\mathrm{Cl}$ in synthesized AgNPs colloid have also been reported; this may be due to the presence of impurities in bacterial supernatant [15].
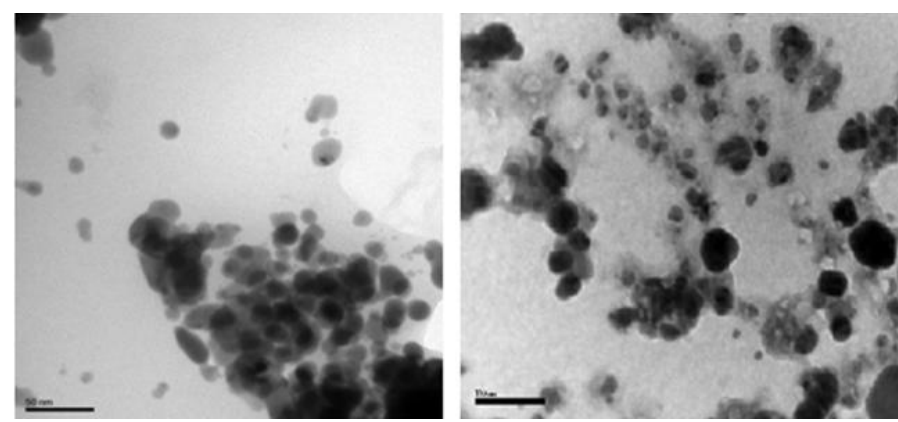

Fig. 2: Transmission electron microscopic (TEM) analysis.

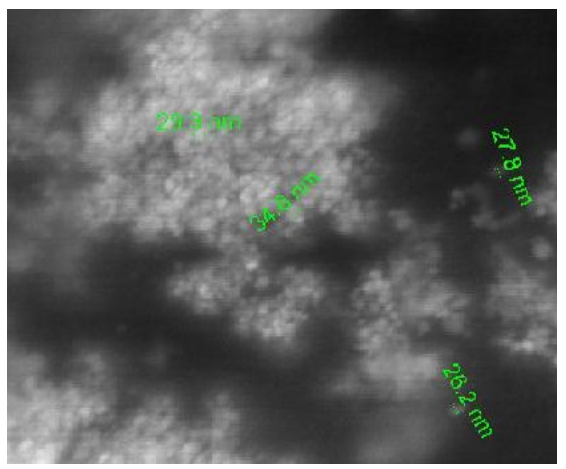

Fig. 3: Scanning electron microscopic analysis of silver nanoparticles

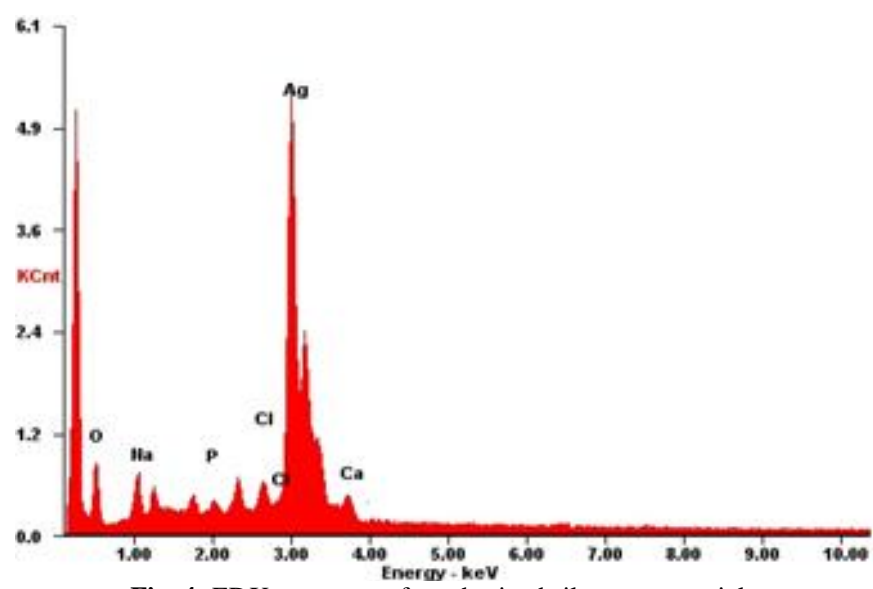

Fig. 4: EDX spectrum of synthesized silver nanoparticles.

FTIR measurements indicate the bio-molecules responsible for reduction of the $\mathrm{Ag}+$ ions to nanoparticle. Absorption peaks were at located about $3339.7,2922.1,2853.51,1639.5,1015,781$ in the region of $-3500-750 \mathrm{~cm}^{-1}$ (Fig. 5).

An FTIR spectrum at different wave numbers reveals their respective functional groups such as: $\mathrm{N}-\mathrm{H}$ stretching vibration, C-H stretching vibration, Alkyl C-H stretching vibration, Amide I, C-O stretching vibration, and residues of $\mathrm{NO}_{3}{ }^{-}$. Whereas the peak for Ag-NPs was found around $520 \mathrm{~cm}^{-1}$. Different functional groups are interpreted to be reducing agents for the biosynthesis of silver nanoparticles and might be present in 
the nitrate reductase enzyme, which is located in the cell surface of Bacillus sp [23]. Silver nanoparticles were found to be spherical in shape (Fig. 6) of about $35 \mathrm{~nm}$ length (represented in their 3D topographic AFM images). Similar AFM results showing silver nanoparticle clusters in the medium have been reported using Bacillus sp. JAPSK2. [24].

\subsection{Decolorization}

Synthetic melanoidin was significantly decolorized by cell free extract, biosynthesized silver nanoparticles, and extract immobilized with AgNPs. Crude extract attained $88 \%$ of decolorization at the end of incubation. The decolorizing ability of extracellular culture supernatant decreases with increase in the time duration, because of unknown enzymatic activities has direct co-relation with decolorization mechanism [25]. Extracellular enzymes such as lignin peroxidase, manganese peroxidase and laccase were reported earlier in various microbial culture supernatants, which involved melanoidin decolorization [26].
Maximum decolorization was found to be $90 \%$ using silver nanoparticles in $15 \mathrm{~h}$ and for crude extract immobilized with AgNPs in 12 h (Fig. 7). Previous study has also reported enhanced rate of color removal proficiency possesed by synthesized AgNPs. Melanoidin removal was gradually increased with increase in process period in nanoparticle mediated decolorization. Similarly higher color removal of $90 \%$ was reported in photocatalytic decolorization of molasses wastewater using $\mathrm{TiO}_{2}$ catalyst [27]. The increased level of decolorization $98 \%$ was obtained in $21 \mathrm{hrs}$ using crude extract immobilized Ag NPs, which enhances the decolorization efficiency by combined catalytic reaction (Fig. 8). Utilization of nanoparticles as a support for enzyme immobilization provides higher specific surface area for binding and improves the efficiency of enzyme activity [28, 29]. Cell free extract immobilized nanoparticles have capability to maintain higher enzyme activity over a wide range of $\mathrm{pH}$ and temperature [30]. Thus, cell free extract immobilized AgNPs were considered as an effective biocatalyst for rapid melanoidin decolorization.

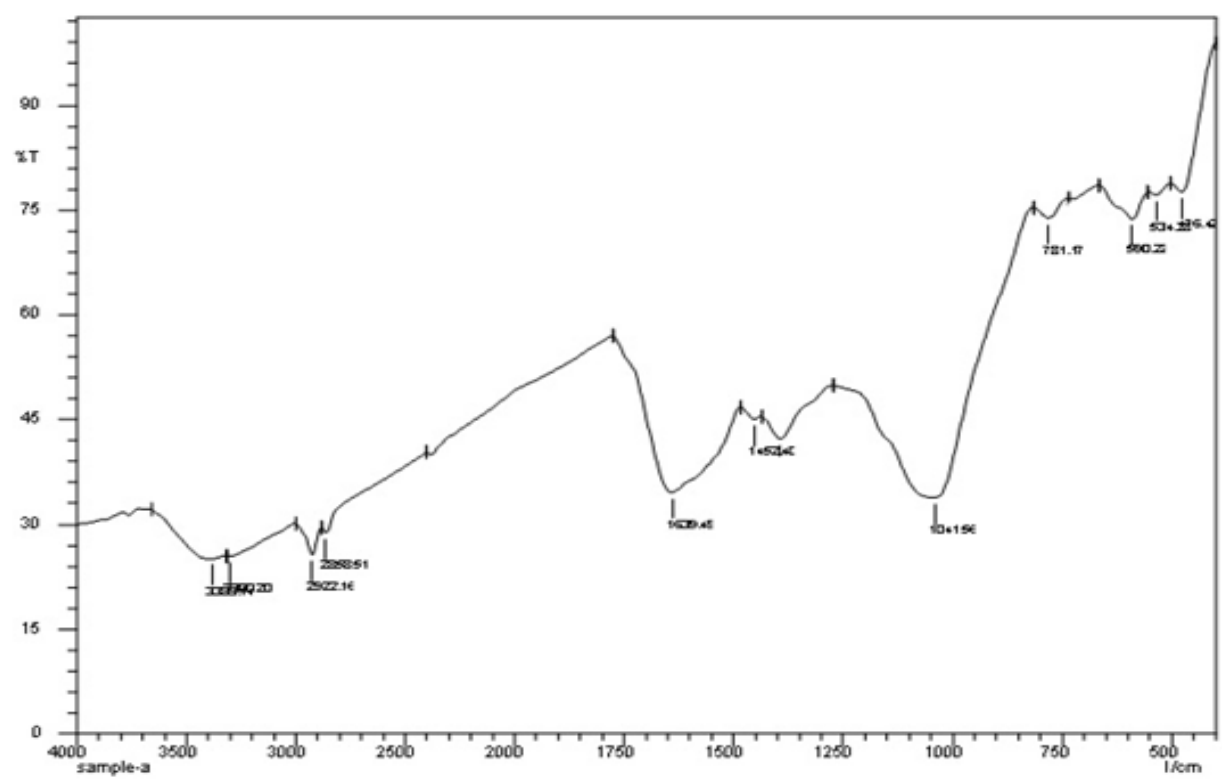

Fig. 5: FT-IR spectrum of silver nanoparticles.
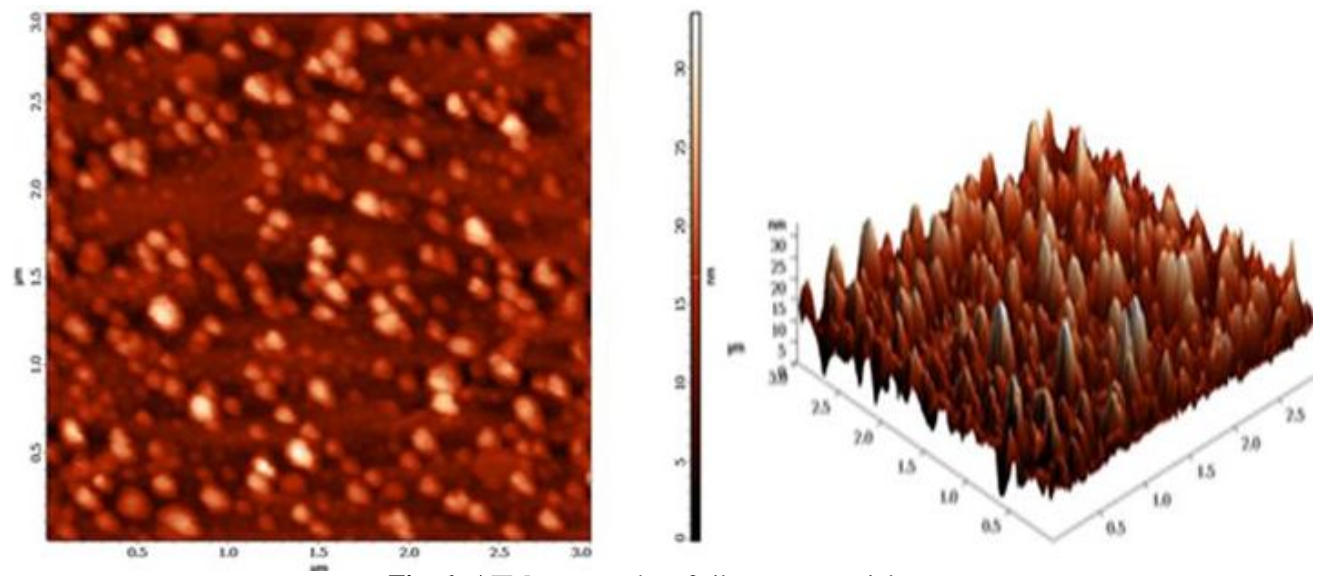

Fig. 6: AFM topography of silver nanoparticles. 


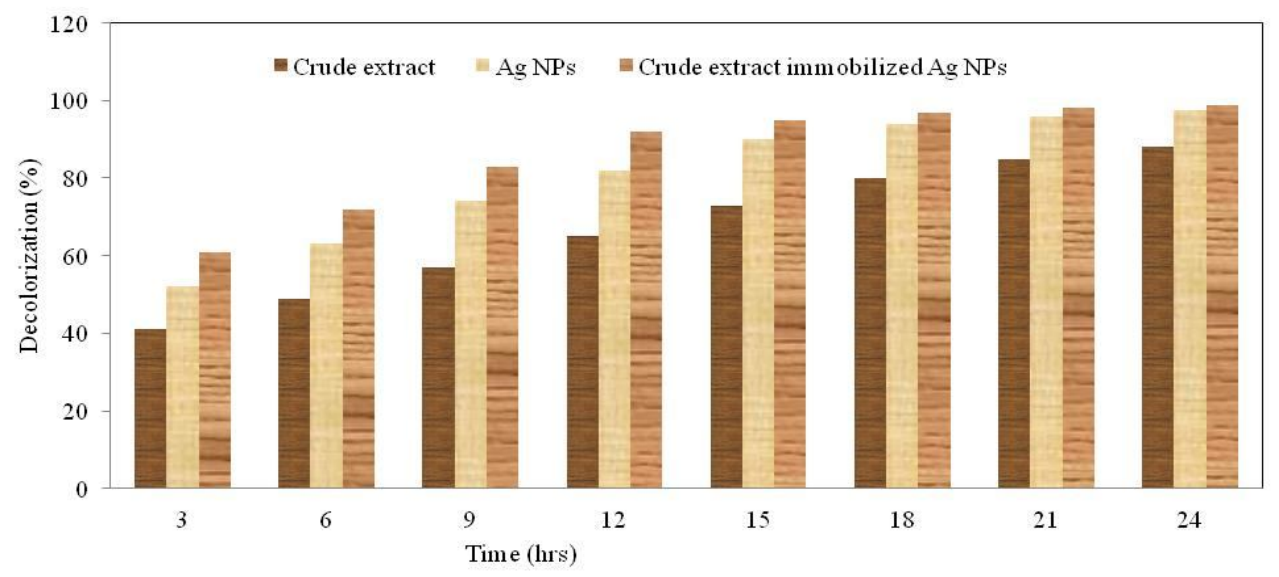

Fig. 7: Decolorization (\%) of melanoidin

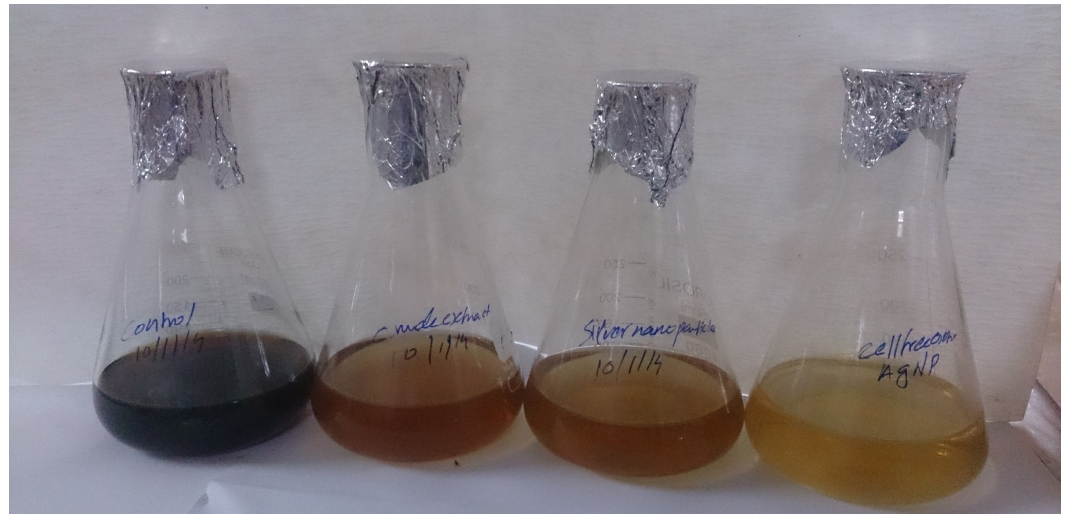

Fig. 8: Decolorization of synthetic melanoidin.

\section{CONCLUSION}

The present study explored the potential of nanomaterial supported immobilization system for rapid melanoidin decolorization. The silver nanoparticles and bacterial extracellular supernatant display significant melanoidin decolorization. Further, the supernatant immobilized with AgNPs also showed higher decolorization activity and this confirms the dual catalytic reaction present in melanoidin degradation. Moreover it suggests that nanocatalyst induces the decolorization process by affecting physico-chemical properties of extracellular supernatant. However findings such as the kind of enzyme responsible for melanoidin decolorization, characteristics of immobilized nanoparticle and free crude extract, are yet to be investigated. From the above points, it can be concluded that nanoparticles associated with microbial source may enhance the efficiency of melanoidin nanobioremdiation in the treatment of molasses spentwash.

\section{ACKNOWLEDGEMENTS}

The authors sincerely thank the management for their constant encouragement and for providing the research facilities in order to complete this work. No conflict of interest exists.

\section{REFERENCES}

1. Chaturvedi, S., Chandra, R., \& Rai, V. Isolation and characterization of Phragmites australis (L.) rhizosphere bacteria from contaminated site for bioremediation of colored distillery effluent. Ecol. Eng., 2006; 27:202-207. http://dx.doi.org/10.1016/j.ecoleng.2006.02.008

2. Reynolds, T.M. Chemistry of nonenzymic browning. I. The reaction between aldoses and amines. Adv. Food Res., 1968; 12:1-52. http://dx.doi.org/10.1016/S0065-2628(08)60005-1

3. Tiwari, S., Rai, P., Yadav, S.K., \& Gaur, R. A novel thermotolerant Pediococcus acidilactici B-25 strain for color, COD, and BOD reduction of distillery effluent for end use applications. Environ Sci Pollut Res., 2013; 20:4046-4058. http://dx.doi.org/10.1007/s11356$\underline{012-1339-5}$

4. Pena, M., Coca, M., Gonzalez, R., Rioja, R., \& Garcia, M.T. Chemical oxidation of waste water from molasses fermentation with ozone. Chemosphere., 2003; 51:893-900. http://dx.doi.org/10.1016/S00456535(03)00159-0

5. Palani velan, R., Rajakumar, S., Suresh S.S. Raja., Ayyasamy, P.M. Optimization of prime parameters for textile dye decolorization by design of experiments (DOEs) using Lysinibacillus fusiformis M1. Desalination and water treatment. 2014. http://dx.doi.org/10.1080/19443994.2014.944583

6. Daneshvar, D., Salari, A., \& Niaei, M. Immobilization of $\mathrm{TiO} 2$ nanopowder on glass beads for the photocatalytic decolorization of an azo dye C.I. Direct Red 23. J. Environ. Sci., 2005; 40:1605-1617.

7. Singh, N.K., Purkayastha, B.D., Roy, J.K., Banik, R.M., \& Yashpal, M. Nanoparticle-induced controlled biodegradation and its mechanism in poly (epsilon-caprolactone). ACS Applied Materials \& Interfaces., 2010; 2:69-81. http://dx.doi.org/10.1021/am900584r 
8. Wang, H., Zhang, W., Zhao, J., Xu, L., Zhou, C., Chang, L., \& Wang, L. Rapid decolorization of phenolic azo dyes by immobilized laccase with $\mathrm{Fe} 3 \mathrm{O} 4 / \mathrm{SiO} 2$ nanoparticles as support. Ind. Eng. Chem. Res., 2013; 52:4401-4407. http://dx.doi.org/10.1021/ie302627c

9. Priyaragini, Veena, S., Swetha, D., Karthik, L., Gaurav K., \& Bhaskara Rao, K.V. Evaluating the effectiveness of marine actinobacterial extract and its mediated titanium dioxide nanoparticle in the degradation of azo dyes. J. Environ. Sci., 2013. http://dx.doi.org/10.1016/S1001-0742(13)60470-2

10. Mukhopadhyay, A., Dasgupta, A.K., Chattopadhyay, D.J., \& Chakrabarti, K. Improvement of thermostability and activity of pectate lyase in the presence of hydroxyapatite nanoparticles. Bioresour. Technol., 2012;

116:348-354. http://dx.doi.org/10.1016/j.biortech.2012.03.094

11. Bhatia, M., Girdhar, A., Chandrakar, B., \& Tiwari, A. Implicating nanoparticles as potential biodegradation enhancers: A Review. J Nanomed Nanotechol. 2013; 4:175.doi:10.4172/2157-7439.1000175. http://dx.doi.org/10.4172/2157-7439.1000175

12. Sadighi, A., \& Faramarzi, M.A. Congo red decolorization by immobilized laccase through chitosan nanoparticles on the glass beads. J. Taiwan Inst. Chem. Eng.2013; 44:156-162. http://dx.doi.org/10.1016/j.jtice.2012.09.012

13. Mahmoodi, N.M. Arabloo, M., \& Abdi, J. Laccase immobilized manganese ferrite nanoparticle: Synthesis and LSSVM intelligent modeling of decolorization. Water Res. 2014; 67:216-226. http://dx.doi.org/10.1016/j.watres.2014.09.011

14. Junejo, Y., Sirajuddin, Baykal, A., Safdar, M., \& Balouch, A. A novel green synthesis and characterization of Ag NPs with its ultra-rapid catalytic reduction of methyl green dye. Appl. Surf. Sci. 2014; 290:499-503. http://dx.doi.org/10.1016/j.apsusc.2013.11.106

15. Vanaja, M., Paulkumar, K., Baburaja, M., Rajeshkumar, S., Gnanajobitha, G., Malarkodi, C., Sivakavinesan, M., \& Annadurai, G. Degradation of methylene blue using biologically synthesized silver nanoparticles. Bioinorganic Chemistry and Applications. 2014; http://dx.doi.org/10.1155/2014/742346.

16. Krutyakov, Y.A., Kudrinskiy, A.A., Olenin, A.Y., \& Lisichkin, G.V. Synthesis and properties of silver nanoparticles: advances and prospects. Russ. Chem. Rev., 2008; 77:233-257. http://dx.doi.org/10.1070/RC2008v077n03ABEH003751

17. Kumar, P., \& Chandra, R. Decolorisation and detoxification of synthetic molasses melanoidins by individual and mixed cultures of Bacillus spp. Bioresour. Technol., 2006; 97: 2096-2102. http://dx.doi.org/10.1016/j.biortech.2005.10.012

18. Das, V.L., Thomas, R., Varghese, R.T., Soniya, E.V., Mathew, J., \& Radhakrishnan, E.K. Extracellular synthesis of silver nanoparticles by the Bacillus strain CS 11 isolated from industrialized area. 3 Biotech., 2014; 4:121-126.

19. Anil Kumar, S., Abyaneh, M.K., Gosavi Sulabha, S.W., Ahmad, A., \& Khan, M.I. Nitrate reductase mediated synthesis of silver nanoparticles from AgNO3. Biotechnol Lett., 2007; 29:439-445. http://dx.doi.org/10.1007/s10529-006-9256-7

20. Kalimuthu, K., Babu, R.S., Venkataraman, D., Mohd, B., \& Gurunathan, S. Biosynthesis of silver nanocrystals by Bacillus licheniformis. Colloids Surf $\quad$ B., 2008; 65:150-153. http://dx.doi.org/10.1016/j.colsurfb.2008.02.018
21. Gurunathan, S., Lee, K.J., Kalishwaralal, K., Sheikpranbabu, S., Vaidyanathan, R., Eom, S.H. Antiangiogenic properties of silver nanoparticles. Biomaterials., 2009; 30:6341-6350. http://dx.doi.org/10.1016/j.biomaterials.2009.08.008

22. Banerjee, P., Sau, S., Das, P., \& Mukhopadhyay, A. Green synthesis of silver nanocomposite for treatment of textile dye. Nanosci Technol., 2014; 1:1-6.

23. Paulkumar, K., Rajeshkumar, S., Gnanajobitha, G., Vanaja, M., Malarkodi, C., Annadurai, G. Biosynthesis of silver chloride nanoparticles using Bacillus subtilis MTCC 3053 and assessment of its antifungal activity. ISRN Nanomaterials., 2013; http://dx.doi.org/10.1155/2013/317963.

24. Nidhi, S., Prasenjit, S., Karthik, R., \& Jayanthi, A. Biosynthesis of silver and selenium nanoparticles by Bacillus sp. JAPSK2 and evaluation of antimicrobial activity. Der Pharmacia Lettre., 2014; 6:175-181.

25. Yadav, S., \& Chandra, R. Biodegradation of organic compounds of molasses melanoidin $(\mathrm{mm})$ from biomethanated distillery spent wash (BMDS) during the decolorization by a potential bacterial consortium. Biodegradation., 2012; 23: 609-620. http://dx.doi.org/10.1007/s10532012-9537-x

26. Hwang, C.F., Jiang, Y.S., Sheu, S.C., Hsieh, P.C., \& Guo, J.H Purification and characterization of a novel glucose oxidase-like melanoidin decolorizing enzyme from Geotrichum sp. No. 56. Afr. J. Microbiol. Res. 2011; 5:3256-3266.

27. Apollo, S., Onyongo, M.S., \& Ochieng, A. UV/H2O2/TiO2/Zeolite Hybrid system for treatment of molasses wastewater. Iran. J. Chem. Chem. Eng., 2014; 33:107-117.

28. Mukhopadhyay, A., Dasgupta, A.K., Chakrabarti, K. Thermostability, $\mathrm{pH}$ stability and dye degrading activity of a bacterial laccase are enhanced in the presence of $\mathrm{Cu} 2 \mathrm{O}$ nanoparticles. Bioresour. Technol., 2013; 127:25-36. http://dx.doi.org/10.1016/j.biortech.2012.09.087

29. Sohn, O.J., Kim, C.K., Rhee, J.I. Immobilization of glucose oxidase and lactate dehydrogenase onto magnetic nanoparticles for bioprocess monitoring system. Biotechnol. Bioprocess Eng., 2008; 13:716-723. http://dx.doi.org/10.1007/s12257-008-0096-2

30. Mohajershojaei, K., Khosravi, A., \& Mahmoodi, N.M. Decolorization of dyes using immobilized laccase enzyme on zinc ferrite nanoparticle from single and binary systems. Fibers Polym., 2014; 15:2139-2145. http://dx.doi.org/10.1007/s12221-014-2139-y

\section{How to cite this article:}

R. Palani velan, P.M. Ayyasamy, R. Kathiravan B. Subashni., Rapid decolorization of synthetic melanoidin by bacterial extract and their mediated silver nanoparticles as support. J App Biol Biotech, 2015; 3 (02): 006-011. 